\title{
Sistemas de produção de feijão intercalado com cafeeiro adensado em período de formação ou após recepa ${ }^{1}$
}

\author{
Abner José de Carvalho², Messias José Bastos de Andrade ${ }^{3}$, Rubens José Guimarães ${ }^{3}$, \\ Augusto Ramalho de Morais ${ }^{4}$
}

\section{RESUMO}

A consorciação de culturas anuais com o cafeeiro é realizada desde a introdução da cafeicultura no Brasil. Entretanto, os últimos resultados disponíveis foram obtidos com cultivares antigos e espaçamentos ultrapassados. Com o objetivo de avaliar o efeito do número de linhas de plantas e da dose de adubação NPK do feijoeiro intercalado ao cafeeiro, foram conduzidos dois experimentos de campo na Universidade Federal de Lavras, um em lavoura em formação (cv. Topázio) e outro em lavoura recepada (cv. Acaiá Cerrado), em duas épocas de plantio (das águas e da seca). O delineamento experimental foi blocos casualizados, com três repetições, sendo os tratamentos distribuídos em esquema fatorial 4 x $4+1$, envolvendo quatro números de linhas intercalares de feijoeiro (uma, duas, três e quatro) e quatro doses de adubação (0, 50, 100 e 150\% da adubação NPK recomendada para o monocultivo), mais um tratamento adicional (o monocultivo do cafeeiro ou do feijoeiro). Concluiu-se que o aumento do número de linhas de feijoeiro elevou o rendimento de grãos da leguminosa em cultivo intercalar ao cafeeiro, independentemente da dose de adubação, do tipo de manejo da lavoura (formação ou recepa) e da época de plantio, mas reduziu o incremento no diâmetro do caule do cafeeiro em formação, a emissão de nós e o crescimento dos ramos plagiotrópicos, tanto no cafeeiro em formação quanto no recepado. O emprego da adubação NPK em até 150\% do equivalente à dose recomendada para o monocultivo não influenciou o rendimento de grãos do feijoeiro intercalado ao cafeeiro.

Palavras-chave: Culturas intercalares, consórcio, Coffea arabica L., Phaseolus vulgaris L., adubação.

\section{ABSTRACT}

\section{Production systems of bean intercropped with establishing coffee crop or after stumping}

Intercropping of annual crops with coffee crop has been used since the introduction of coffee cultivation in Brazil. However, the last available results have been obtained with old cultivars and exceeded distance between lines. Aiming to study the effect of row numbers and NPK doses applied to bean intercropped with coffee trees, two field experiments were conducted at the Federal University of Lavras. The experiments were carried out in two commercial coffee crops: establishing cv. Topázio and cv. Acaiá stumped at $40 \mathrm{~cm}$ from the soil level. Both coffee crops were intercropped with bean in the dry and the rainy seasons. The experiments were arranged in randomized blocks design, with three replicates and a 4 x $4+1$ factorial scheme, involving four numbers of intercalar rows of bean (one, two, three and four

\footnotetext{
Recebido para publicação em julho de 2008 e aprovado em maio de 2010

${ }^{1}$ Parte da dissertação de mestrado em Fitotecnia do primeiro autor. Apoio: CAPES, CNPq e FAPEMIG.

Engenheiro-Agrônomo, Doutor. Departamento de Ciências Agrárias da Universidade Estadual de Montes Claros. Avenida Reinaldo Viana, 2630, Bico da Pedra, C.P. 91, 39440000, Janaúba, Minas Gerais (MG), Brasil. abjocar@yahoo.com.br

${ }^{3}$ Engenheiros-Agrônomos, Doutores. Departamento de Agricultura da Universidade Federal de Lavras, Campus Universitário, C.P. 3037, 37200-000, Lavras, MG, Brasil. mandrade@ufla.br, rubensjg@ufla.br

${ }^{4}$ Engenheiro-Agrônomo, Doutor. Departamento de Ciências Exatas da Universidade Federal de Lavras, Campus Universitário, C.P. 3037, 37200-000, Lavras, MG, Brasil. armorais@ufla.br
} 
) and four doses of the NPK fertilization recommended for the bean monoculture (0, 50, 100 and 150\%), and an additional treatment (monoculture of coffee or bean). The results allowed to conclude that the increase in the number of bean rows increased the legume grain yield in intercropping with coffee, regardless of the fertilization dose, the crop management (establishing or stumping) and year season, but reduced the increase in stem diameter of the establishing coffee crop, node emission and growth of plagiotropic branches both in the establishing and stumping coffee plants. NPK fertilization equivalent to up to $150 \%$ of the dose recommended for bean monoculture did not influence grain yield of the legume intercropped with coffee plants.

Key words: Coffea arabica L., fertilization, intercropping, Phaseolus vulgaris L.,.

\section{INTRODUÇÃO}

Desde o início da cafeicultura no Brasil são utilizadas culturas intercalares, principalmente na formação ou renovação da lavoura. A fase inicial de implantação da cafeicultura apresenta custo muito elevado e, além disso, o seu retorno econômico inicia-se somente a partir do terceiro ano. Assim, o uso de culturas intercalares proporciona renda imediata ao cafeicultor, reduzindo os custos de formação da lavoura (Vieira, 1985; Guimarães et al., 2002a).

Nas principais regiões cafeeiras do Brasil, o feijão é a cultura intercalar mais comum e tem despertado o interesse da pesquisa para trazer informações sobre o uso deste tipo de cultivo pelos produtores. Vários estudos (Melles \& Silva, 1978; Begazo, 1984; Chebabi, 1984; Melles et al., 1985; Chaves \& Guerreiro, 1989) destacam o feijão, principalmente a espécie Phaseolus vulgaris L., como uma das melhores culturas para o cultivo intercalar com o cafeeiro. De acordo com Vieira (2006), o feijoeiro é preferido para os consórcios culturais por se tratar de cultura de ciclo curto, pouco competitiva, semeada em diferentes épocas do ano, relativamente tolerante à competição movida pela planta consorte, ser um dos alimentos básicos do povo brasileiro e por, frequentemente, alcançar bons preços no mercado.

A maior parte desses estudos, entretanto, foi conduzida com cultivares e espaçamentos já ultrapassados. Atualmente, as lavouras cafeeiras são implantadas em espaçamentos mais adensados, exigindo dos cafeicultores podas periódicas, interrompendo a produção de café por até dois anos (Guimarães et al., 2002b; Mendes et al., 2002). Dessa forma, as culturas intercalares contribuem para a renda do cafeicultor por ocasião da recepa das plantas de café.

O objetivo do presente estudo foi determinar o número de linhas e a dose de adubação NPK do feijoeiro intercalado ao cafezal que apresenta maior produtividade sem comprometer o desenvolvimento do cafeeiro em formação ou recepado.

\section{MATERIAL E MÉTODOS}

Os experimentos de campo foram conduzidos no setor de Cafeicultura do Departamento de Agricultura da Universidade Federal de Lavras (UFLA). O primeiro experimento (talhão1) foi instalado em lavoura cafeeira do cv. Topázio, implantada em fevereiro de 2003 no espaçamento de $2 \mathrm{~m}$ entre linhas e 0,6 entre plantas. $\mathrm{O}$ segundo (talhão 2) foi conduzido em lavoura do cv. Acaiá Cerrado, implantada no mesmo espaçamento do talhão $1 \mathrm{e}$ em fase de recuperação após recepa a $40 \mathrm{~cm}$ do solo, realizada em agosto de 2003. O feijão, cv. BRS-MG Talismã, foi semeado, em cada talhão de café e em monocultivo, em duas épocas subseqüentes: nas águas, com plantio em novembro de 2003 e colheita em fevereiro de 2004, e na da seca, com plantio em março e colheita em junho de 2004, sempre no espaçamento de $0,5 \mathrm{~m}$ entre linhas e densidade de 15 sementes por metro linear. A semeadura do feijão na época da seca ocorreu nas mesmas parcelas na das águas.

Os tratamentos foram dispostos em esquema fatorial envolvendo quatro números de linhas intercalares de plantas de feijão (uma, duas, três e quatro linhas) e quatro doses de adubação do feijoeiro (0, 50, 100 e 150\% da adubação NPK recomendada para o monocultivo), mais os monocultivos do feijão e do café, conduzidos como tratamentos adicionais. O delineamento experimental utilizado foi o de blocos casualizados com três repetições.

No caso do cafeeiro, as parcelas foram constituídas por três fileiras de 10 plantas, sendo a fileira central utilizada para as avaliações. Assim, tanto para o cafeeiro quanto para o feijoeiro as parcelas constaram de $6 \times 4 \mathrm{~m}$, perfazendo $24 \mathrm{~m}^{2}$ de área total. As avaliações do cafeeiro, tanto no consórcio quanto no monocultivo, ocorreram em ramos previamente marcados em quatro plantas previamente escolhidas na fileira central do cafeeiro. Aárea útil de cada parcela foi de $12 \mathrm{~m}^{2}$, mantendo-se nos tratamentos consorciados a proporcionalidade entre o número de linhas de ambas as espécies. No feijão solteiro, a área útil correspondeu às quatro linhas centrais de uma parcela de oito linhas. 
O solo das áreas experimentais foi classificado como Latossolo Vermelho distroférrico típico (Embrapa, 1999), originalmente sob vegetação de cerrado. O cálculo da necessidade de calagem, realizado de acordo com o método de saturação por bases (Alvarez V \& Ribeiro, 1999), não indicou a necessidade de correção da acidez do solo no talhão com cafeeiro em formação, bem como na área com feijoeiro em monocultivo. No talhão com cafeeiro recepado, o cálculo mostrou a necessidade de aplicação de 2,2 toneladas de calcário por hectare. O calcário utilizado foi o calcítico, com PRNT em torno de 90\%, distribuído em área total e incorporado com gradagem leve nas entrelinhas do cafeeiro.

Em ambos os talhões, o cafeeiro foi adubado conforme Guimarães et al. (1999). A adubação de referência (100\%) do feijoeiro foi a recomendada para o nível 2 de tecnologia por Chagas et al. (1999), e constou de $20 \mathrm{~kg}$ de $\mathrm{N} \mathrm{ha}^{-1}$ (uréia), $40 \mathrm{~kg}$ de $\mathrm{P}_{2} \mathrm{O}_{5}$ ha-1 $^{-1}$ (superfosfato triplo) e $20 \mathrm{~kg}$ de $\mathrm{K}_{2} \mathrm{O}$ ha $^{-1}$ (cloreto de potássio) no plantio e $30 \mathrm{~kg}$ de $\mathrm{N} \mathrm{ha}^{-1}$ (ureia) em cobertura convencional sem incorporação.

O preparo do solo foi convencional, sendo as atividades realizadas com o intuito de deixá-lo em condições adequadas para a semeadura baseadas no seu revolvimento. No monocultivo do feijoeiro foram realizadas uma aração e uma gradagem antes de cada época de plantio. Já nos talhões consorciados, foi realizada uma gradagem leve nas entrelinhas do cafeeiro antes do plantio das águas e uma capina manual antes do plantio da seca. Em todos os casos, o sulcamento e a semeadura do feijoeiro foram manuais. No plantio das águas, o feijão intercalado foi capinado manualmente, enquanto na seca, procedeu-se o controle químico das plantas daninhas com a aplicação direcionada de fomesafen + fluazifop-butil, em pós-emergência, na dosagem de $1 \mathrm{~L}$ do produto comercial Robust por hectare (Ferreira et al., 1998). As plantas de cafeeiro recepado, tanto no consórcio quanto no monocultivo, passaram por duas operações de desbrota, aproximadamente aos 90 e 150 dias após a recepa, de maneira a deixar apenas um broto por planta.

No feijoeiro avalariam-se a altura média de plantas $(\mathrm{cm})$, estimada pela medição do comprimento da haste principal em amostra casual de 10 plantas, e o rendimento de grãos (kg.ha-1) com seus componentes primários (número de vagens por planta, número de grãos por vagem e massa média de 100 grãos). O número de vagens por planta foi estimado pela contagem do número total de vagens na mesma amostra de 10 plantas. Para a estimativa do número médio de grãos por vagem, foi contado o número total de grãos de 50 vagens tomadas ao acaso da amostra anterior. A massa média de 100 grãos (g) foi determinada a partir da pesagem de três amostras de 100 grãos, e o rendimento de grãos foi apurado pela pesagem da produção total da parcela útil. Tanto a massa média de 100 grãos quanto o rendimento de grãos foram corrigidos para $13 \%$ de umidade.

Quanto ao cafeeiro, foram avaliados o número de nós e o comprimento dos ramos ortotrópicos (haste principal) e plagiotrópicos (ramos laterais), além do diâmetro do caule. As contagens do número de nós e a medição do comprimento do ramo plagiotrópico ocorreram sempre em ramos previamente marcados. No cafeeiro recepado as medições do ramo ortotrópico foram realizadas no broto remanescente. O diâmetro foi medido na altura do colo (cafeeiro em formação) ou a $5 \mathrm{~cm}$ acima da inserção do broto (no cafeeiro recepado). Foram realizadas duas avaliações no cafeeiro: a primeira antes da semeadura do feijão das águas e a segunda, após a segunda colheita do feijão da seca, sendo considerados para análise os incrementos verificados no período.

Os dados obtidos foram submetidos à análise de variâncias individual e conjunta (Pimentel Gomes, 2000), envolvendo os dois tipos de lavoura cafeeira e as duas épocas de plantio, utilizando-se para os cálculos o pacote computacional Sisvar (Ferreira, 2000). As médias do tratamento adicional e do fatorial, assim como as dos tipos de lavoura e das épocas de plantio, foram comparadas pelo teste F a 5\% de probabilidade. Para as fontes de variação, realizou-se análise de variância das regressões linear e múltipla, selecionando-se o modelo adequado por meio do Teste F, a 5\% de probabilidade, e do valor do coeficiente de determinação $\left(\mathrm{R}^{2}\right)$.

\section{RESULTADOS E DISCUSSÃO}

\section{Parâmetros do feijoeiro}

O aumento da adubação NPK causou aumento linear da altura de plantas de feijoeiro (Figura 1a). Certamente, a maior disponibilidade de nutrientes proporcionou maior crescimento da haste principal do feijoeiro, tal como já verificado por outros autores (Silva, 1985; Souza et al., 2003; Souza et al., 2005).

A altura de plantas do feijoeiro também foi influenciada pela época de plantio e pelo tipo de manejo da lavoura (cafeeiro em formação ou recepado). Na época das águas, apesar da maior disponibilidade hídrica, a altura de plantas de feijoeiro foi inferior (Tabela 1), discordando do obtido em monocultivo por Souza (2000). Entretanto, outros fatores, além de água e nutrientes, podem ter concorrido para esse resultado, como a competição por luz. Uma vez que as duas épocas de plantio (águas e seca) foram subsequentes, na da seca, que foi a segunda a ser plantada, devido ao crescimento das plantas do cafeeiro, o feijoeiro certamente sofreu maior efeito do sombreamento produzido pelas plantas de café, provocando alongamento do caule das plantas de feijão. O efeito do sombreamento no alongamento do caule do feijoeiro já foi estudado por vários pesquisadores 
(Portes \& Silveira, 1982; Lopes et al., 1983), os quais verificaram que quanto mais baixa a densidade do fluxo de luz maior o alongamento do caule do feijoeiro. Segundo Taiz \& Zeiger (1991), esse alongamento da haste é resultante de uma menor fotodegradação de auxina no meristema apical quando a incidência de luz é reduzida.

Com relação ao tipo de manejo da lavoura cafeeira, observa-se que, no cafeeiro em formação, o feijoeiro alcançou maior altura (Tabela 1), certamente em função da menor competição exercida sobre a leguminosa nesse talhão, em relação ao talhão com cafeeiro recepado, que, além do maior porte, apresenta sistema radicular mais desenvolvido, sendo, portanto, potencialmente mais competitivo com o feijoeiro.

No plantio das águas, quando se comparou o feijoeiro em monocultivo com o consorciado, constatou-se que a altura da leguminosa foi superior no monocultivo, indicando que a associação, independentemente do número de linhas intercalares, reduz o seu crescimento. O efeito prejudicial da competição interespecífica sobre o feijoeiro em sistemas de cultivo consorciado é amplamente relatado na literatura. Vieira (1999) comentou que, em sistemas de consórcio entre milho e feijão semeados simultaneamente, o feijoeiro consorciado sofre redução de rendimento, que varia entre 20 e 70\% em relação ao rendimento alcançado no monocultivo.

O número médio de vagens por planta aumentou de forma quadrática com o aumento da adubação NPK do feijoeiro, decrescendo depois do nível de $100 \%$ da aduba- ção de referência (Figura 1b). Esse comportamento está de acordo com outros resultados já obtidos (Silva, 1985; Pachêco, 1993; Souza et al., 2003). O comportamento do número de vagens por planta também foi diferenciado em função do tipo de manejo da lavoura e da época de plantio, bem como da interação entre estes fatores. No plantio das águas, o número de vagens por planta foi superior ao observado no da seca (Tabela 1), certamente em razão das melhores condições climáticas, como maior precipitação pluvial e melhor distribuição das chuvas, principalmente por ocasião da floração, o que favorece a formação e o não abortamento de flores (Andrade et al., 2006), resultando, consequentemente, em maior número de vagens por planta. De forma análoga, a análise de variância mostrou que, no plantio das águas, o feijoeiro intercalado ao cafeeiro recepado apresentou maior número de vagens em relação ao cafeeiro em formação. No plantio da seca, a resposta dessa característica não apresentou diferenças significativas entre os dois tipos de lavoura. Nesse último plantio, é comum as chuvas escassearem antes da floração ou formação de vagens, causando aborto de flores ou vagens (Andrade et al., 2006).

Na medida em que se aumentou o número de linhas intercalares de plantas de feijão, o número médio de grãos por vagem apresentou ligeira redução linear (Figura 1c). Certamente, esse efeito foi causado pelo aumento da competição intraespecífica entre os feijoeiros. Esse resultado é coerente com os obtidos em monocultivo por Souza et al. (2003), nos quais o aumento da população de plantas

Tabela 1. Altura de plantas (AP) (cm), número de vagens por planta (VP), número de grãos por vagem (GV), massa de 100 grãos (M100) (g) e rendimento de grãos (RG) $\left(\mathrm{kg} \mathrm{ha}^{-1}\right)$ do feijoeiro intercalado com o cafeeiro em formação ou após a recepa. Nas duas épocas de plantio (nas águas e seca) ${ }^{1}$.

\begin{tabular}{lcccccc}
\hline & & AP & VP & GV & M100 & RG \\
\hline Épocas de plantio & Águas & $69,5 \mathrm{~b}$ & $15,7 \mathrm{a}$ & $4,9 \mathrm{a}$ & $24,59 \mathrm{a}$ & $2080 \mathrm{a}$ \\
& Seca & $74,3 \mathrm{a}$ & $9,7 \mathrm{~b}$ & $5,0 \mathrm{a}$ & $22,25 \mathrm{~b}$ & $1127 \mathrm{~b}$ \\
\hline Lavoura & Formação & $74,1 \mathrm{a}$ & $12,1 \mathrm{~b}$ & $5,1 \mathrm{a}$ & $22,99 \mathrm{~b}$ & $1581 \mathrm{a}$ \\
& Recepado & $69,7 \mathrm{~b}$ & $13,3 \mathrm{a}$ & $4,8 \mathrm{~b}$ & $23,84 \mathrm{a}$ & $1626 \mathrm{a}$ \\
\hline $\mathrm{N}^{\text {l linhas }}$ & 1 linha & 70,8 & 12,6 & 5,2 & 23,45 & 830 \\
& 2 linhas & 73,0 & 13,4 & 4,9 & 23,30 & 1400 \\
& 3 linhas & 72,1 & 12,6 & 4,9 & 23,56 & 1906 \\
& 4 linhas & 71,8 & 12,2 & 4,9 & 23,38 & 2278 \\
\hline Adubação & 0.0 & 67,1 & 11,7 & 5,0 & 23,48 & 1547 \\
& 0.5 & 73,1 & 12,8 & 4,9 & 23,42 & 1651 \\
& 1.0 & 74,4 & 13,4 & 4,9 & 23,43 & 1601 \\
\hline Consórcio (águas) & 1.5 & 73,0 & 12,9 & 5,1 & 23,34 & 1616 \\
Monocultivo (águas) & & $69,5 \mathrm{~b}$ & $15,7 \mathrm{a}$ & $4,9 \mathrm{~b}$ & $24,59 \mathrm{a}$ & $2080 \mathrm{~b}$ \\
\hline Consórcio (seca) & & $82,9 \mathrm{a}$ & $19,1 \mathrm{a}$ & $5,3 \mathrm{a}$ & $22,25 \mathrm{~b}$ & $3558 \mathrm{a}$ \\
\hline Monocultivo (seca) & & $74,3 \mathrm{a}$ & $9,7 \mathrm{a}$ & $5,0 \mathrm{a}$ & $22,25 \mathrm{a}$ & $1127 \mathrm{~b}$ \\
\hline Média geral & $75,7 \mathrm{a}$ & $10,0 \mathrm{a}$ & $4,6 \mathrm{~b}$ & $22,55 \mathrm{a}$ & $1764 \mathrm{a}$ \\
\hline
\end{tabular}

${ }^{1}$ Dentro de cada fator, médias seguidas por diferentes letras nas colunas diferem significativamente pelo teste $\mathrm{F}$ a $5 \%$ de probabilidade.

Rev. Ceres, Viçosa, v. 57, n.3, p. 383-392, mai/jun, 2010 
reduziu o número médio de grãos por vagem, mas discorda dos obtidos por outros autores (Portes \& Carvalho, 1983; Ramalho et al., 1985), que, trabalhando com o consórcio de milho e feijão, não encontraram efeito do consorciamento com o milho sobre o número de grãos de feijão por vagem. O aumento da dose de fertilizante em até $150 \%$ da dose recomendada para o monocultivo do feijoeiro não afetou, de maneira significativa, o número médio de grãos por vagem. Entretanto, esse componente de produção foi influenciado pelo tipo de manejo da lavoura cafeeira. No talhão com café em formação, devido à menor competição interespecífica, foi maior o número de grãos por vagem. Deve ser observado, ainda, que nas duas épocas de plantio estudadas a média do consórcio diferiu da média do monocultivo no que diz respeito ao número de grãos por vagem. Nota-se, entretanto, que esse efeito foi de pequena magnitude e, de certa forma, não coerente nas duas épocas (Tabela 1).

A massa média de grãos apresentou comportamento ligeiramente diferenciado em função do número de linhas intercalares e da adubação NPK do feijoeiro em cada época de plantio e tipo de manejo da lavoura. O desdobramento da interação quádrupla época de plantio (P) x lavoura (La) x número de linhas (NL) x adubação (A) revelou significância das doses de adubação do feijoeiro dos tratamentos com três linhas intercalares no cafeeiro em formação tanto no plantio das águas como no da seca (Figura 1d). O incremento da adubação NPK do feijoeiro ocasionou aumento linear na massa média de 100 grãos no plantio das águas, mas ocasionou ligeira redução da mesma característica no plantio da seca. Esse efeito, entretanto, mostrou-se pouco consistente e de pequena magnitude. Além disso, deve ser observado que, a julgar pelos valores do $\mathrm{R}^{2}$, os dados mostraram pequeno ajuste.

O desdobramento da interação tripla época de plantio (P) x manejo da lavoura (La) x número de linhas (NL) revelou que o rendimento de grãos do feijoeiro respondeu de forma quadrática ao aumento do número de linhas intercalares. Entretanto, o incremento do rendimento de grãos foi diferenciado, dependendo da época de plantio e do tipo de

(a)
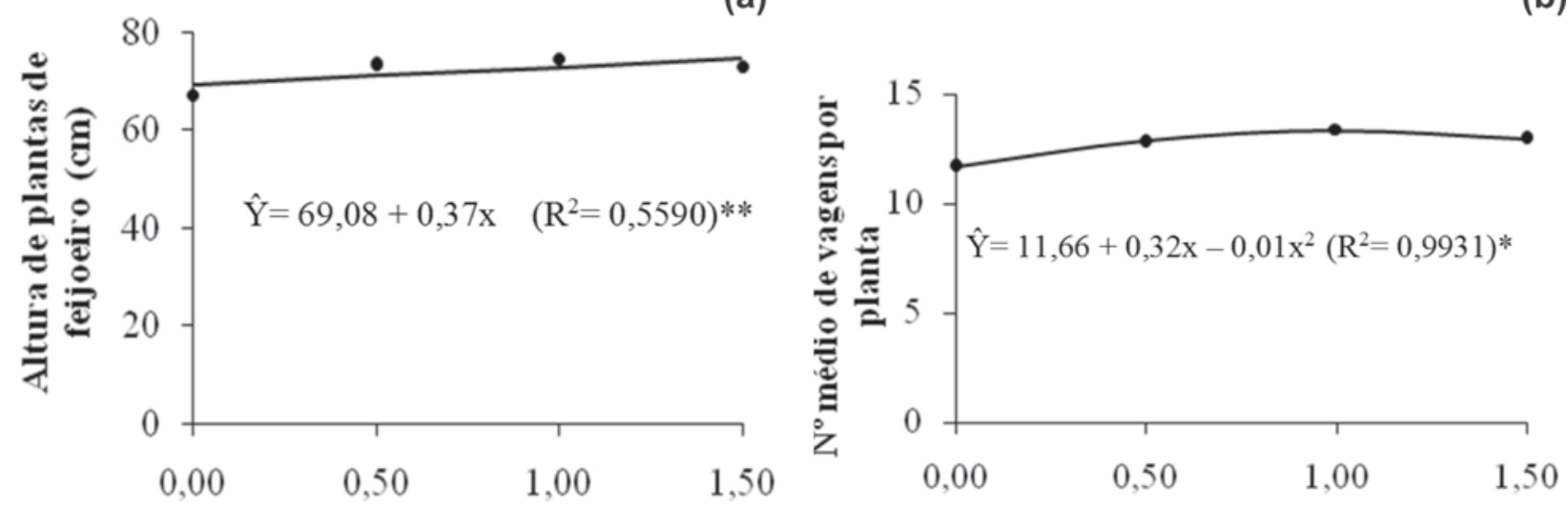

Doses de adubação NPK do feijoeiro

Doses de adub ação NPK do feijoeiro
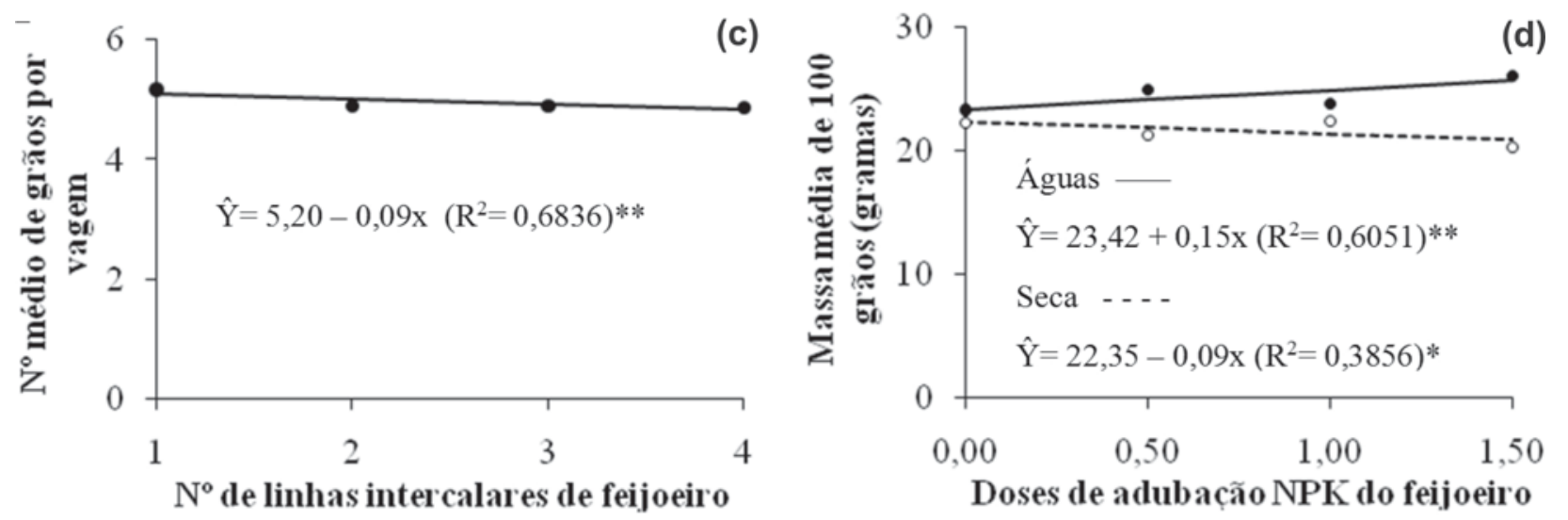

Figura 1. Altura de plantas de feijoeiro (a); número médio de vagens por planta (b); número médio de grãos por vagem (c), em função das doses de adubação ou do número de linhas de feijoeiro intercalado ao cafeeiro em formação ou recepado, nas épocas de plantio das águas e da seca; e massa média de 100 grãos (d) do feijoeiro consorciado com o cafeeiro em formação, utilizando-se três linhas intercalares, em função das doses de adubação do feijoeiro e das épocas de plantio estudadas. UFLA, Lavras, MG, 2004. 
manejo da lavoura cafeeira (Figura 2). Tanto intercalado ao cafeeiro em formação quanto ao recepado o aumento no número de linhas intercalares proporcionou acréscimo no rendimento de grãos de feijão. Em ambos os tipos de lavoura do cafeeiro o rendimento de grãos no plantio das águas foi superior ao do plantio da seca (Tabela 1).

Esses resultados indicam que, visando apenas à produção de grãos de feijão, o emprego de quatro linhas intercalares leva à maior produção da leguminosa. No cafeeiro em formação, quatro linhas intercalares de feijoeiro produziram cerca de 3.200 kg.ha-1 no plantio das águas e pouco menos de $1.400 \mathrm{~kg} \cdot \mathrm{ha}^{-1}$ no da seca. No cafeeiro recepado esses rendimentos foram, respectivamente, em torno de 2.700 e $1.800 \mathrm{~kg} . \mathrm{ha}^{-1}$. Os rendimentos obtidos no plantio das águas, nos dois tipos de lavoura, podem ser considerados excepcionais em relação às produtividades médias obtidas na mesma safra no Brasil e em Minas Gerais, que foram, respectivamente, da ordem de 807 e 1.240 kg.ha-1 (IBGE, 2007). Os componentes de produção que contribuíram para essa maior produtividade no plantio das águas foram o maior número de vagens por planta e a maior massa média de grãos (Tabela 1), que, certamente, são resultado das condições climáticas mais favoráveis naquela época de plantio, principalmente da maior precipitação pluvial e da melhor distribuição das chuvas naquele período.

Ao contrário do que ocorreu com o número de linhas intercalares, o incremento da adubação NPK do feijoeiro em até $150 \%$ da adubação recomendada para o seu monocultivo não representou qualquer aumento no rendimento de grãos da leguminosa (Tabela 1). É provável que esse resultado esteja relacionado com a boa fertilidade inicial dos solos das glebas de café utilizadas. Deve ser ainda considerado que o emprego de pequenas doses de adubação do feijoeiro, mesmo não resultando em baixa produtividade da leguminosa, pode refletir em prejuízos

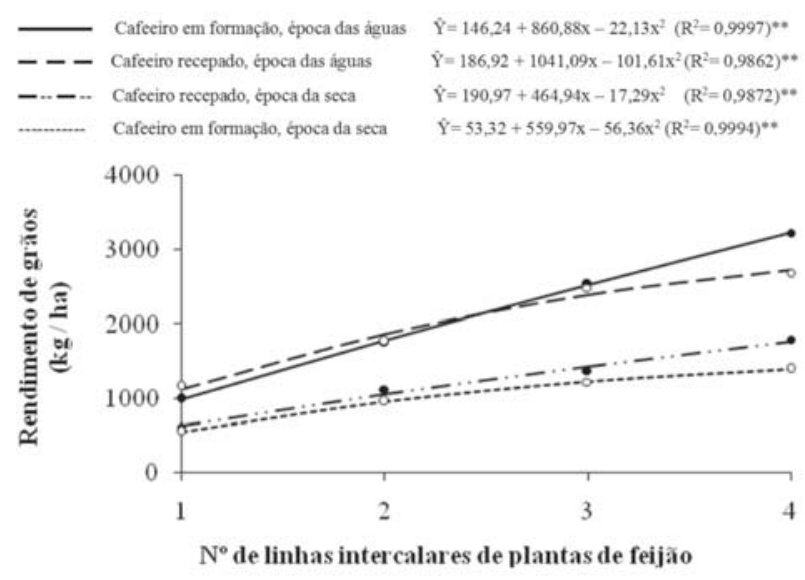

Figura 2. Rendimento de grãos de feijoeiro (kg.ha-1), em função do número de linhas de plantas de feijão intercalares ao cafeeiro, de acordo com o tipo de manejo da lavoura (em formação ou recepado) e com a época de plantio (águas ou seca). ao cafezal, levando à menor produção de café ou comprometendo o desenvolvimento do cafeeiro (Guimarães et al., 2002a).

\section{Parâmetros do cafeeiro}

\section{Cafeeiro em formação}

A emissão de nós no ramo ortotrópico e o incremento na altura de plantas do cafeeiro não foram influenciados pelos tratamentos (Tabela 2), mostrando que, mesmo nos casos de maior população de plantas de feijão, a competição da cultura intercalar não chegou a alterar o padrão de
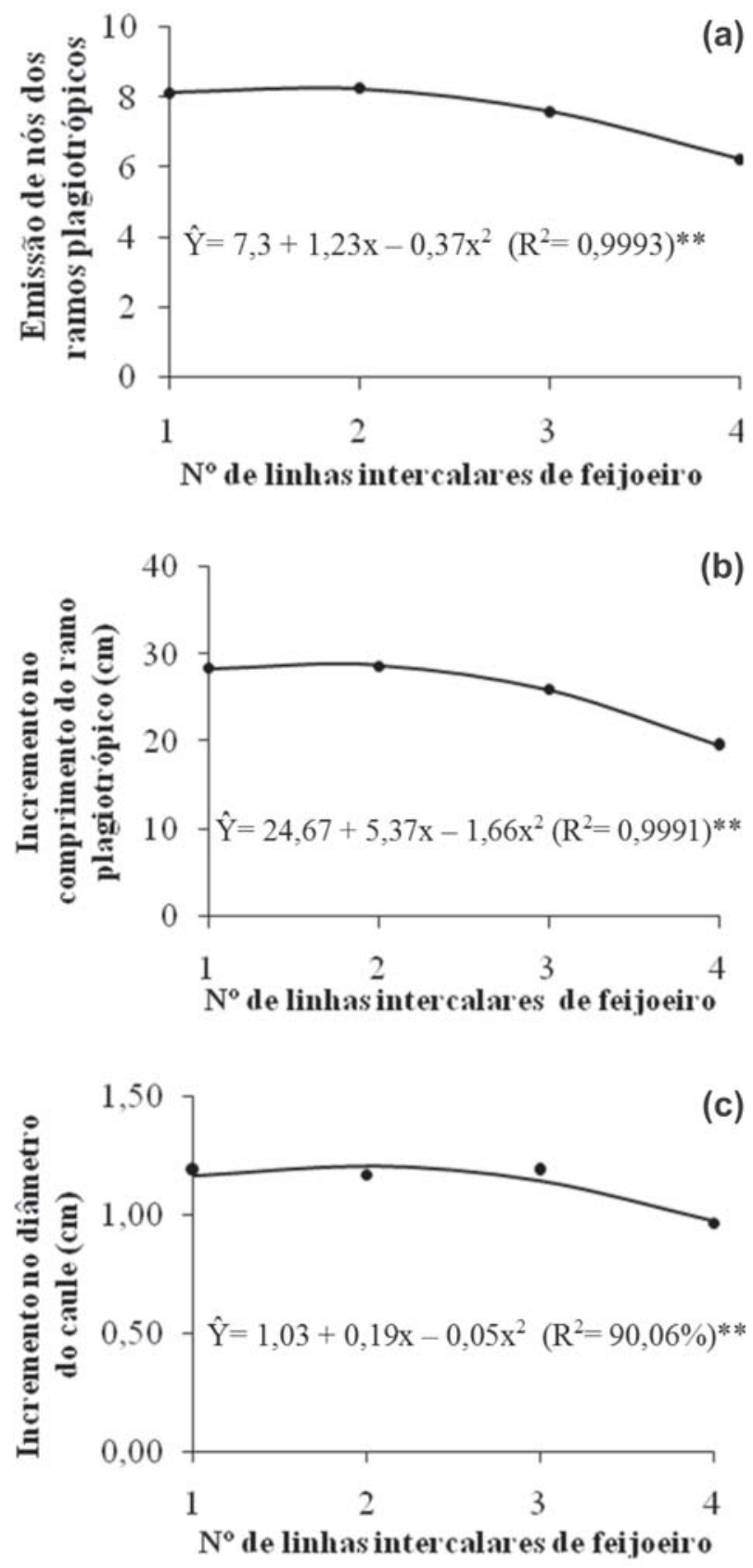

Figura 3. Emissão de nós (a); incremento do comprimento dos ramos plagiotrópicos (b); e incremento no diâmetro do caule (c) do cafeeiro em formação, em função do número de linhas intercalares do feijoeiro. 
crescimento daquele ramo do cafeeiro. Esses resultados estão de acordo com os encontrados por Carvalho et al. (2007), que, estudando o consórcio de feijão-comum com cafeeiro adensado recém-plantado, verificaram que a emissão de pares de folhas e o incremento na altura das plantas de cafeeiro não foram afetados pela população de plantas ou pela adubação NPK do feijoeiro.

A emissão de nós e o incremento no comprimento do ramo plagiotrópico e no diâmetro do caule do cafeeiro foram afetados significativamente pelo número de linhas intercalares de plantas de feijoeiro (Tabela 2). A partir de duas linhas intercalares, a emissão de nós dos ramos plagiotrópicos decresceu de acordo com um modelo quadrático (Figura 3a), indicando que, a partir de duas linhas de feijoeiro, a produtividade do cafeeiro pode vir a ser afetada, pois nos nós dos ramos plagiotrópicos é que se desenvolverão as gemas reprodutivas do cafeeiro. Do mesmo modo, o aumento no comprimento desses ramos também seguiu um comportamento quadrático de formato parecido com o anterior (Figura 3b), o que pode ser explicado pela interdependência das duas variáveis, mostrando que a presença do feijoeiro restringiu o crescimento dos ramos laterais, principalmente quando em maior número de linhas intercalares. O aumento do número de linhas intercalares de feijoeiro provocou redução no incremento do diâmetro do caule do cafeeiro (Figura 3c), o que se deve, certamente, à maior pressão de competição interespecífica pelos fatores de produção, provocada pelo incremento do número de linhas da cultura consorte. Carvalho et al. (2007) também verificaram ligeira redução no incremento do diâmetro do caule de cafeeiros recém-plantados provocada pelo aumento do número de linhas intercalares de plantas de feijão.

Melles \& Silva (1978), intercalando as culturas de arroz, milho, soja, feijão e feijão-de-porco, em diferentes densidades de plantio, com cafeeiro em espaçamento convencional (4,0 x 1,0 m), nos dois primeiros anos de formação, observaram que em alguns tratamentos consorcia- dos, inclusive três linhas de feijoeiro, a produção de café na primeira colheita foi maior que no monocultivo do cafeeiro, talvez pela proteção contra ventos e pelo sombreamento causado pela presença das culturas intercalares. Melles et al. (1985) recomendaram o plantio de, no máximo, uma linha de feijão intercalado com cafeeiro em formação no espaçamento de 2,0 m entre linhas. Entretanto, nas condições em que o presente estudo foi conduzido, somente a partir de três linhas intercalares de plantas de feijoeiro houve efeitos negativos no desenvolvimento do cafeeiro.

O contraste entre a média dos tratamentos consorciados e o monocultivo do cafeeiro mostrou-se significativo apenas para o incremento no comprimento do ramo plagiotrópico, tendo a média do monocultivo $(32,05 \mathrm{~cm})$ sido ligeiramente superior à do consórcio $(25,65 \mathrm{~cm})$. As doses de adubação da leguminosa, por sua vez, não influenciaram significativamente nenhuma das características de crescimento do cafeeiro. Cabe lembrar que o desenvolvimento e a produtividade do cafeeiro podem ser comprometidos pela utilização, em longo prazo, de doses reduzidas ou pela ausência da adubação da leguminosa quando do uso como cultura intercalar (Guimarães et al., 2002a). A interação NL x A foi não-significativa, evidenciando que o número de linhas intercalares e a adubação do feijoeiro não dependeram um do outro, mostrando efeitos independentes.

\section{Cafeeiro recepado}

A análise de variância mostrou que o número de linhas intercalares de plantas de feijoeiro influenciou significativamente as características relacionadas aos ramos laterais, ou seja, a emissão de nós e o comprimento dos ramos plagiotrópicos oriundos das brotações dos caules das plantas de café recepadas. Tanto a emissão de nós (Figura 4a) quanto o incremento no comprimento daquele ramo (Figura 4b) decresceram, de acordo com o comportamento quadrático, a partir da utilização de três linhas intercalares, o que mostra a interdependência entre as duas

Tabela 2. Análise de variância dos dados relativos à emissão de nós no ramo ortotrópico (NO) e no ramo plagiotrópico (NP), incremento no comprimento do ramo plagiotrópico (CP), na altura de planta (AP) e no diâmetro do caule (DC) do cafeeiro cv. Topázio consorciado com feijoeiro, cultivado nas épocas das águas e da seca.

\begin{tabular}{|c|c|c|c|c|c|c|}
\hline \multirow{2}{*}{$\begin{array}{l}\text { Fontes de } \\
\text { variação }\end{array}$} & \multicolumn{6}{|c|}{ Quadrado Médio } \\
\hline & GL & NO & NP & $\mathbf{C P}$ & AP & DC \\
\hline Bloco & 2 & $0,55 \mathrm{~ns}$ & $0,97 \mathrm{~ns}$ & $45,75 \mathrm{~ns}$ & 54,36 ns & $0,10 *$ \\
\hline Tratamento & 16 & $0,99 \mathrm{~ns}$ & $2,94 *$ & $64,73 * *$ & $39,04 \mathrm{~ns}$ & $0,05 \mathrm{~ns}$ \\
\hline $\mathrm{N}^{\mathrm{o}}$ linhas (NL) & 3 & $0,97 \mathrm{~ns}$ & $10,38 * *$ & $215,85 * *$ & $31,06 \mathrm{~ns}$ & $0,14 * *$ \\
\hline Adubação (A) & 3 & $1,21 \mathrm{~ns}$ & $0,48 \mathrm{~ns}$ & 13,31 ns & 25,76 ns & $0,02 \mathrm{~ns}$ \\
\hline NL x A & 9 & $1,03 \mathrm{~ns}$ & $1,03 \mathrm{~ns}$ & $25,80 \mathrm{~ns}$ & 39,17 ns & $0,03 \mathrm{~ns}$ \\
\hline Fat $\mathrm{x}$ adicional & 1 & $0,08 \mathrm{~ns}$ & $5,11 \mathrm{~ns}$ & $115,94 *$ & $101,56 \mathrm{~ns}$ & $0,09 \mathrm{~ns}$ \\
\hline Resíduo & 32 & 1,70 & 1,35 & 19,51 & 36,75 & 0,03 \\
\hline$\overline{\mathrm{CV}(\%)}$ & & 19,55 & 15,18 & 16,97 & 18,04 & 14,37 \\
\hline
\end{tabular}

**, * Significativo, respectivamente, a 1 e $5 \%$ de probabilidade pelo teste $\mathrm{F}$. 
variáveis, fato também ocorrido no cafeeiro em formação. Entretanto, no caso da emissão de nós, esse efeito foi de pequena magnitude e, a julgar pelos valores do $\mathrm{R}^{2}$, os dados mostraram pequeno ajuste ao modelo selecionado. É possível que a presença do feijoeiro tenha limitado o crescimento dos ramos laterais, principalmente em maior número de linhas intercalares, assim como aconteceu no cafeeiro em formação. Esse comportamento é fácil de ser entendido quando se verifica a competitividade do
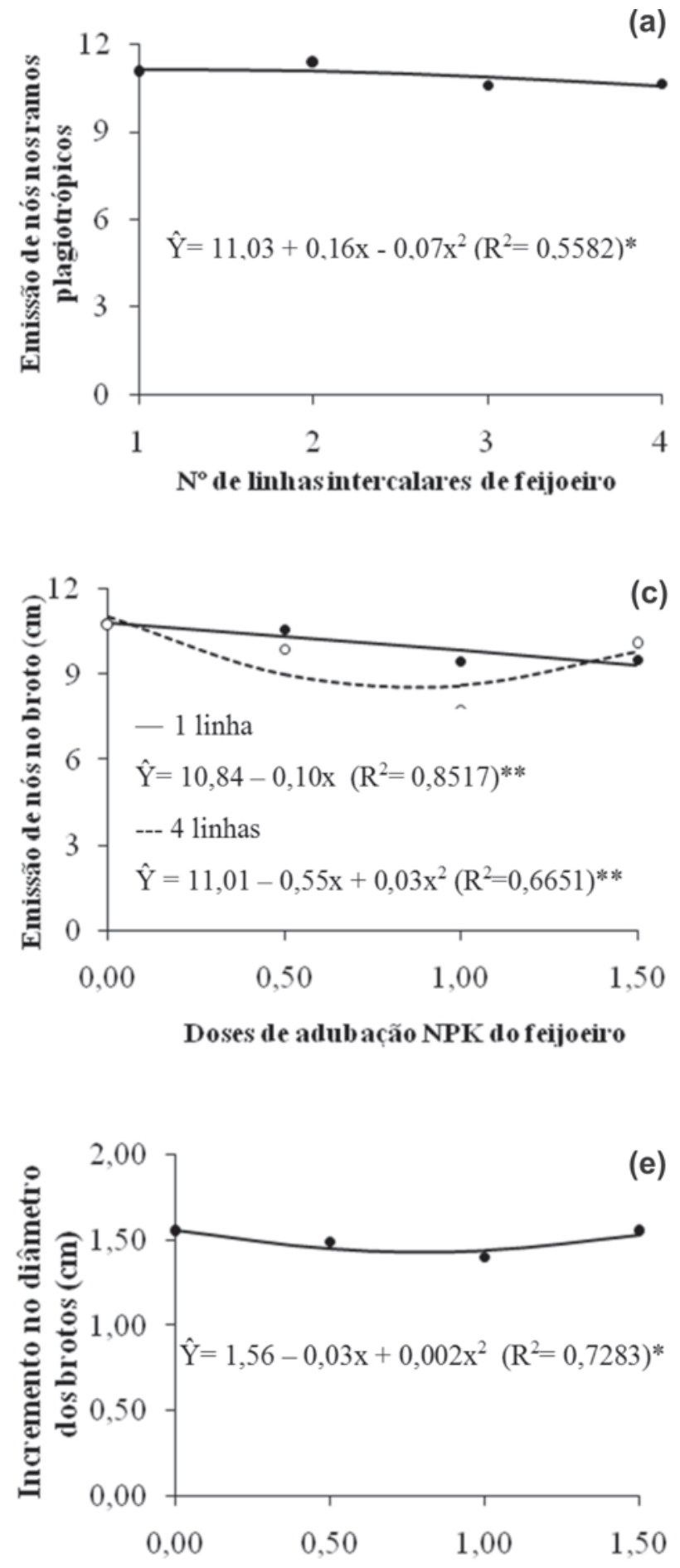

Doses de adubação NPK do feijoeiro feijoeiro sobre os cafeeiros nos casos de três e quatro linhas intercalares. Por sua vez, as doses de adubação NPK do feijoeiro afetaram de maneira significativa as características relacionadas ao ramo principal, que são o número de nós do ramo ortotrópico, o comprimento e o diâmetro do broto. A interação número de linhas (NL) x adubação (A) mostrou-se significativa apenas para emissão de nós do ramo ortotrópico (brotação). O desdobramento do efeito das doses de adubação dentro de cada
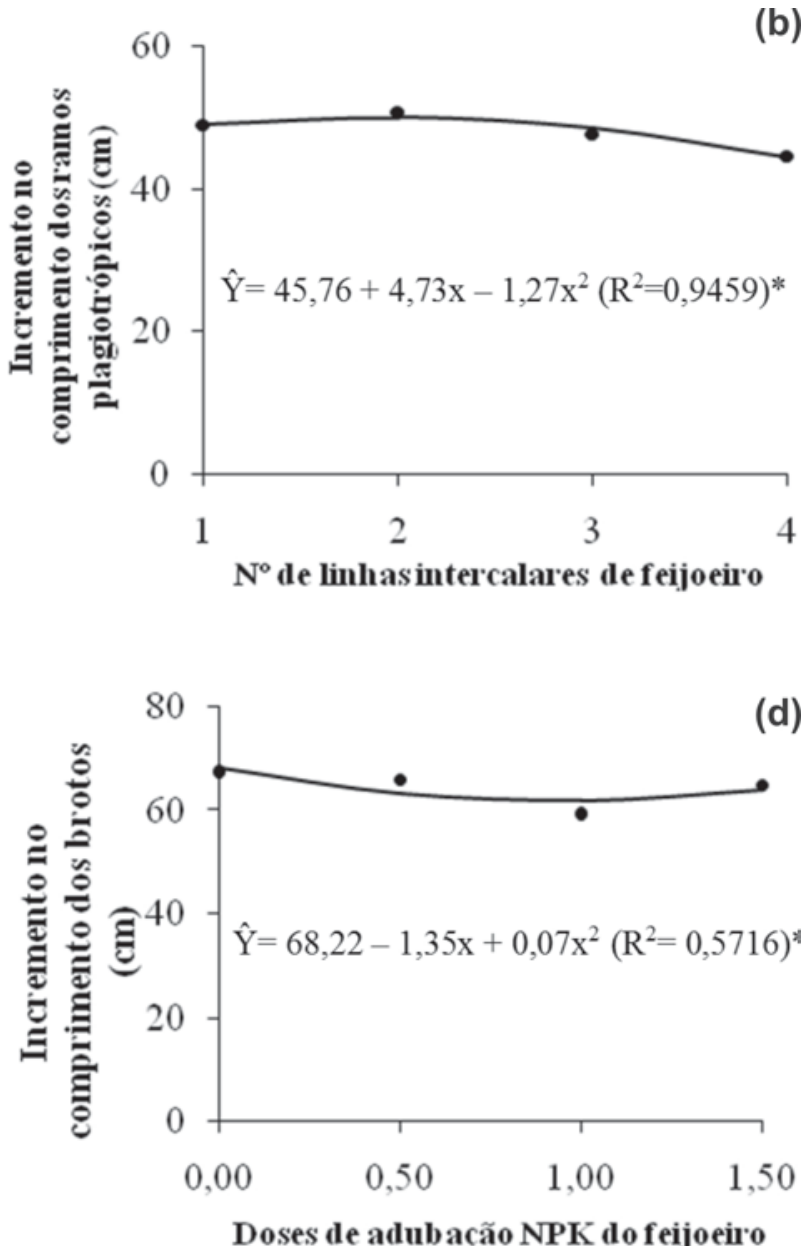

(d)

Figura 4. Emissão de nós (a); e incremento no comprimento dos ramos plagiotrópicos (b); emissão de nós (c); incremento no comprimento (d); e no diâmetro do broto (e) remanescente do cafeeiro, em função do número de linhas intercalares ou da dose de adubação NPK do feijoeiro, em cultivo consorciado com cafeeiro recepado. 
número de linhas intercalares revelou significância nos casos de uma e quatro linhas de feijoeiro (Figura 4c). Esses efeitos, entretanto, foram pouco consistentes, com baixo $\mathrm{R}^{2}$ e de pequena magnitude.

O incremento do comprimento dos brotos remanescentes respondeu de maneira quadrática aos níveis de adubação do feijoeiro. $\mathrm{O}$ aumento da adubação do feijoeiro de 0 (sem adubação) para 0,5 (metade da dose recomendada) e para 1,0 (100\% da dose recomendada) provocou redução no aumento da altura das plantas de cafeeiro, que voltou a aumentar com a utilização da adubação 1,5, equivalente a $150 \%$ da dose recomendada para o feijoeiro em monocultivo (Figura 4d). No entanto, a julgar pelo baixo valor do $\mathrm{R}^{2}$, o ajuste dos dados à equação não foi satisfatório. As respostas do aumento no diâmetro do broto remanescente à adubação do feijoeiro foram de natureza quadrática (Figura 4e), tendo, a partir da dose de $100 \%$ da adubação recomendada para o feijoeiro, os valores sido crescentes. O contraste fatorial vs adicional não foi significativo em nenhum dos casos.

Alguns autores (Chaves et al., 1976; Chaves, 1977), estudando os efeitos do uso de culturas intercalares em cafezais recepados, concluíram que o plantio do feijoeiro a 1,0 m de distância da linha do cafezal não prejudicou o crescimento em altura e diâmetro do broto do cafeeiro. No presente estudo, somente nos tratamentos com uma linha de feijoeiro a distância foi equivalente à observada pelos citados autores. Chaves (1978), por sua vez, considerando o cultivo de culturas intercalares até a segunda produção de cafeeiros recepados, verificou que, nos tratamentos consorciados, a produção de café foi ligeiramente superior à do cafeeiro em monocultivo.

É importante ressaltar também que, embora os efeitos da adubação do feijoeiro não tenham sido consistentes neste estudo, o desenvolvimento e a produtividade do cafeeiro podem ser comprometidos pela utilização, em longo prazo, de doses reduzidas ou pela ausência da adubação da leguminosa como cultura intercalar.

\section{CONCLUSÕES}

Em lavouras de café adensado (2 m entre linhas), tanto para o cafeeiro em formação quanto para o recepado, é possível o uso de até duas linhas intercalares de feijoeiro. A partir de três linhas, houve diminuição na emissão de nós e no incremento do comprimento dos ramos plagiotrópicos do cafeeiro.

O emprego de adubação NPK equivalente a até 150\% da dose recomendada para o monocultivo do feijoeiro não influenciou o rendimento de grãos da leguminosa em cultivo intercalar ao cafeeiro em formação ou recepado, bem como a quase totalidade das características avaliadas no cafeeiro.

\section{REFERÊNCIAS}

Alvarez V VH \& Ribeiro AC (1999) Calagem. In: Ribeiro AC, Guimarães PTG \& Alvarez V VH (Eds.) Recomendações para o uso de corretivos e fertilizantes em Minas Gerais - 5a Aproximação. Viçosa, CFSEMG. p.43-60.

Andrade MJB de, Carvalho AJ de \& Vieira NMB (2006) Exigências edafoclimáticas. In: Vieira C, Paula Júnior TJ de \& Borém A (Eds.) Feijão. 2. ed. Viçosa, UFV. p.67-86.

Begazo JCEO (1984) Considerações sobre o feijão como cultura consorciada do cafezal e mandiocal. Informe Agropecuário, 10:50-51.

Carvalho AJ de, Andrade MJB de \& Guimarães RJ (2007) Sistemas de produção de feijão intercalado com cafeeiro adensado recém-plantado. Ciência e Agrotecnologia, 31:133-139.

Chagas JM, Braga JM, Vieira C, Salgado LT, Junqueira Neto A, Araújo GAA, Andrade MJB de, Lana RMQ \& Ribeiro AC (1999) Feijão. In: Ribeiro AC, Guimarães PTG \& Alvarez V VH (Eds.) Recomendações para o uso de corretivos e fertilizantes em Minas Gerais - 5a Aproximação. Viçosa, CFSEMG. p.306-307.

Chaves JCD (1977) Estudos de culturas intercalares em cafezais recepados no Paraná. In: V Congresso Brasileiro de Pesquisas Cafeeiras, Guaraparí. Resumos. IBC-GERCA. p.62-64.

Chaves JCD (1978) Estudos de culturas intercalares em cafezais recepados e em formação. In: VI Congresso Brasileiro de Pesquisas Cafeeiras, Ribeirão Preto, Resumos. IBC-GERCA. p.125-127.

Chaves JCD, Garcia A, Assumpção LC, Kranz WM \& Colassante O (1976) Estudos de culturas intercalares em cafezais recepados no Paraná. In: IV Congresso Brasileiro de Pesquisas Cafeeiras, Caxambú. Resumos. IBC-GERCA. p.173-175.

Chaves JCD \& Guerreiro E (1989) Culturas intercalares em lavouras cafeeiras. Pesquisa Agropecuária Brasileira, 24:177-190.

Chebabi MAA (1984) Influência da competição nutricional de culturas anuais (arroz, milho, feijão e soja), no desenvolvimento do cafeeiro (Coffea arabica L.). Dissertação de Mestrado. Lavras, Escola Superior de Agricultura de Lavras. 72p.

EMBRAPA - Empresa Brasileira de Pesquisa Agropecuária (1999) Sistema brasileiro de classificação de solos. Brasília. 412p.

Ferreira DF (2000) Análise estatística por meio do SISVAR para Windows versão 4.0. In: Reunião anual da região brasileira da Sociedade Internacional de Biometria. São Carlos, Programa e Resumo. UFSCar. p.235.

Ferreira FA, Silva AA, Cobucci T \& Ferreira LR (1998) Manejo de plantas daninhas. In: Vieira C, Paula Jr TJ de \& Borém A (Eds.) Feijão: Aspectos gerias e cultura no Estado de Minas Gerais. Viçosa, UFV. p.325-356.

Guimarães PTG, Garcia AWR, Alvarez V VH, Prezotti LC, Viana AS, Miguel AE, Malavolta E, Corrêa JB, Lopes AS, Nogueira FD, Monteiro AVC \& Oliveira JA de (1999) Cafeeiro. In: Ribeiro AC, Guimarães PTG \& Alvarez V. VH (Eds.) Recomendações para o uso de corretivos e fertilizantes em Minas Gerais $-5^{\text {a }}$ Aproximação. Viçosa, CFSEMG. p.289-302.

Guimarães RJ, Mendes ANG \& Souza CAS (2002a) Culturas intercalares. In: Guimarães RJ, Mendes ANG \& Souza CAS (Eds.) Cafeicultura. Lavras, Indi Gráfica Editora. p.247-257.

Guimarães RJ, Mendes ANG \& Souza CAS (2002b) Podas do cafeeiro: Época, tipos de poda, podas x densamento da lavoura. In: Guimarães RJ, Mendes ANG \& Souza CAS (Eds.) Cafeicultura. Lavras, Indi Gráfica Editora. p.182-193.

IBGE - Instituto Brasileiro de Geografia e Estatística (2007) Produção agrícola municipal. Disponível em: <http:// www.sidra.ibge.gov.br/bda/tabela/protabl.asp? $\mathrm{z}=\mathrm{p} \& \mathrm{o}=20 \& \mathrm{i}=\mathrm{P}>$ Acessado em: 28 de setembro de 2007. 
Lopes NF, Oliva MA, Melges E, Furtado MH \& Freitas JG de (1983) Crescimento, morfologia, partição de assimilados e produção de matéria seca do feijão (Phaseolus vulgaris L.) submetido a três densidades do fluxo radiante. Revista Ceres, 30:451-462.

Melles CCA, Chebabi MAA, Nacif AP \& Guimarães PTG (1985) Culturas intercalares em lavouras cafeeiras nas fases de formação e produção. Informe Agropecuário, 126:65-68.

Melles CCA \& Silva CM (1978) Culturas intercalares. Informe Agropecuário, 4:70-71.

Mendes ANG, Guimarães RJ \& Souza CAS (2002) Implantação da lavoura: espaçamento e sistemas de plantio, preparo e conservação do solo, plantio, planejamento dos tratos culturais e colheita. In: Guimarães RJ, Mendes ANG \& Souza CAS (Eds.) Cafeicultura. Lavras, Indi Gráfica Editora. p.160-181.

Pachêco RG (1993) Efeitos de espaçamento e adubação sobre dois cultivares de feijão (Phaseolus vulgaris L.). Dissertação de Mestrado. Viçosa, Universidade Federal de Viçosa. 64p.

Pimentel Gomes F (2000) Curso de estatística experimental. 14 ed. Piracicaba, Escola Superior de Agricultura "Luiz de Queiroz”. 467p.

Portes T de A \& Carvalho JRP de (1983) Área foliar, radiação solar, temperatura do ar e rendimentos em consorciação e em monocultivo de diferentes cultivares de milho e feijão. Pesquisa Agropecuária Brasileira, 18:755-762.

Portes T de A \& Silveira PM (1982) Efeito do sombreamento artificial sobre características morfológicas e produção de grãos em feijão (Phaseolus vulgaris L.). In: Reunião Nacional de Pesquisa de Feijão, Goiânia. Anais, EMBRAPA/CNPAF. p.151-153.
Ramalho MAP, Coelho AM \& Teixeira ALS (1985) Consórcio de milho verde e feijão em diferentes épocas de plantio na entressafra. Pesquisa Agropecuária Brasileira, 20:799-806.

Silva DB (1985) Efeitos de populações de plantas, adubação e variedades sobre a produtividade do feijoeiro comum (Phaseolus vulgaris L.). Dissertação de Mestrado. Lavras, Escola Superior de Agricultura de Lavras. 48p.

Souza AB de (2000) Populações de plantas, níveis de adubação e calagem para o feijoeiro (Phaseolus vulgaris L.) num solo de baixa fertilidade. Tese de Doutorado. Lavras, Universidade Federal de Lavras. 69p.

Souza AB de, Andrade MJB de \& Muniz JA (2003) Altura de planta e componentes do rendimento do feijoeiro em função de população de plantas, adubação e calagem. Ciência e Agrotecnologia, 27:1205-1213.

Souza AB de, Andrade MJB de \& Vieira NMB (2005) Populações de plantas, adubação e calagem para o feijoeiro no distrito de Itaiacoca em Ponta Grossa - PR. In: VIII Congresso Nacional de Pesquisa de Feijão. CONAFE. Anais, Goiânia. p.1054-1057.

Taiz L \& Zeiger E (1991) Plant physiology. Califórnia, The Benjamin/Cummings Publishings Company. 565p.

Vieira C (1985) O feijão em cultivos consorciados. Viçosa, UFV. $134 \mathrm{p}$.

Vieira C (1999) Estudo monográfico do consórcio milho-feijão no Brasil. Viçosa, UFV. 183p.

Vieira C (2006) Cultivos consorciados. In: Vieira C, Paula Jr TJ de \& Borém A (Eds.) Feijão. 2. ed. Viçosa, UFV. p.493-528. 